Brit. f. industr. Med., 1968, 25, 139.

\title{
Determination of Lead in Urine by Atomic Absorption Spectrophotometry ${ }^{\mathrm{r}}$
}

\author{
STIG SELANDER and KIM CRAMÉR \\ with the technical assistance of BIRGITTA BORJESSON and GUNILLA MANDORF
}

From Medical Service I and from the Department of Hygiene, University of Göteborg, Göteborg, Sweden

\begin{abstract}
A method for the determination of lead in urine by means of atomic absorption spectrophotometry (AAS) is described. A combination of wet ashing and extraction with ammonium pyrrolidine dithiocarbamate into isobutylmethylketone was used. The sensitivity was about $0.02 \mu \mathrm{g} . / \mathrm{ml}$. for $\mathrm{I} \%$ absorption, and the detection limit was about $0.02 \mu \mathrm{g}$. $/ \mathrm{ml}$. with an instrumental setting convenient for routine analyses of urines. Using the scale expansion technique, the detection limit was below $0.01 \mu \mathrm{g} . / \mathrm{ml}$., but it was found easier to determine urinary lead concentrations below $0.05 \mu \mathrm{g} . / \mathrm{ml}$. by concentrating the lead in the organic solvent by increasing the volume of urine or decreasing that of the solvent. The method was applied to fresh urines, stored urines, and to urines, obtained during treatment with chelating agents, of patients with lead poisoning. Urines with added inorganic lead were not used. The results agreed well with those obtained with a colorimetric dithizone extraction method $(r=0.989)$. The AAS method is somewhat more simple and allows the determination of smaller lead concentrations.
\end{abstract}

Since the initial work of Walsh (1955) atomic absorption spectrophotometry (AAS) has found increasing use for the determination of small quantities of various metals. Recent reviews of principles and applications have been published by Zettner (1964), Willis (1965), and Slavin (1965), and a very complete bibliography was given by Slavin (1966).

The instrumentation, e.g., lamps and burners, has been successively improved, which has enhanced the sensitivity and extended the range of application of the method. Techniques have also been improved by the development of extraction methods. The metal is bound to a complexing agent and extracted into an organic solvent (Allan, 196r; Willis, 1962; Pierce and Cholak, 1966; Zettner, Sylvia, and Capacho-Delgado, 1966). Solvent extraction, sometimes preceded by the ashing of the sample, eliminates interference by such things as serum constituents and high salt concentrations, and also makes it possible to concentrate the metal, thereby increasing the analytical sensitivity.

\footnotetext{
1 Aided by grants No. B-66-374 and No. B-67-6IP-2094-0I from the Swedish Medical Research Council and by a grant from Forsakringsforetaget Folksam, Stockholm.

Received for publication October 13, 1967.
}

The determination of lead in urine is important in toxicology and industrial hygiene. Several AAS methods have been described-simple procedures without any preparation of the samples (Slavin, Sprague, Rieders, and Cordova, 1964; Pierce and Cholak, 1966) and more elaborate ones which include ashing and/or extraction with organic solvents (Willis, 1962; Berman, 1964; Slavin and Sprague, 1964; Pierce and Cholak, 1966). However, some of the methods are not free from objections. The most important objection is that, in general, they have been tested by the recovery of inorganic lead compounds added to normal urine. One cannot assume that the same methods are applicable to pathological urines containing organic lead compounds or lead bound by chelating agents during treatment of lead poisoning or during a diagnostic mobilization test. The validity of a method must be judged by comparing the results of analyses of pathological urines with those obtained with another, well-established method.

We have found that direct AAS analysis, i.e., direct aspiration of the urine sample, is a very insensitive method. One can measure only very high lead concentrations, and the values are substantially lower than those obtained with the colorimetric dithizone extraction method of Bess- 
man and Layne (1955), which we have used for several years in our laboratory.

When lead was complexed with ammonium pyrrolidine dithiocarbamate (APDC) without preashing and was extracted with isobutylmethylketone, the recovery of added inorganic lead was satisfactory, although the values showed a tendency to be somewhat low. But analyses of pathological urine samples gave much lower values than those obtained with the colorimetric dithizone method, which includes wet ashing. Thus both ashing and solvent extraction seem necessary for reliable analyses of fresh or stored pathological urines, including those from patients treated with chelating agents. Such a method, including extraction of the metal with APDC into isobutylmethylketone, is given by Willis (1962). We have developed a modification of his method, using a different ashing procedure which does not involve the danger of explosions and which enables smaller sample volumes to be used.

\section{Materials and Methods}

Instrumentation A Perkin-Elmer atomic absorption spectrophotometer, model 303, with a three-slot Boling burner and a neon-filled hollow cathode lamp of standard type was used. The instrument was equipped with a digital concentration readout accessory (DCR-I) and a Hitachi recorder.

The DCR-I gives values directly in absorbence and it may also be calibrated to give values in concentration units. If a DCR-I is not used, the absorption values given by the model 303 must be converted into absorbence (special tables are provided by Perkin-Elmer) before constructing a calibration curve.

Instrumental Settings Wavelength: $2170 \AA$. (217 nm) or $2833 \AA$. $(283.3 \mathrm{~nm})$, slit, 4 ; lamp current, Io $\mathrm{mA}$; air pressure, $2 \mathrm{~kg} . / \mathrm{cm}^{2}$ (30 p.s.i.); flow, 9.5 (instrument scale reading); acetylene pressure, $0.5 \mathrm{~kg} . / \mathrm{cm} .{ }^{2}$ (7.5 p.s.i.); flow, 5. The atomizer must be adjusted to give maximal absorption during aspiration of a lead standard in isobutylmethylketone. The aspiration rate of the sample should be about $3 \mathrm{ml}$./minute. The recorder was put at noise suppression 2 and scale expansion $\times 1$. These settings are given only as guides and may, of course, be varied, depending on the instrumental conditions.

Reagents All are of analytical grade.

Hydrochloric Acid, 5.0 N.

Digestion Reagent 5 volumes of conc. nitric acid and 2 volumes of conc. sulphuric acid.

Hydrogen Peroxide, Ioo vol.

Ammonia, concentrated.

Ammonium Pyrrolidine Dithiocarbamate (APDC) solution, $2 \%$. A fresh solution should be prepared each day and filtered before use.

Isobutylmethylketone, water-saturated. Two volumes of isobutylmethylketone and I volume of water are mixed in a separating funnel, shaken for 20 minutes, and allowed to stand for Io minutes, after which the water phase is run off and the solvent phase is decanted.

Lead Standard, I,000 $\mu \mathrm{g} . / \mathrm{ml}$. Lead nitrate, I,600 mg., and conc. nitric acid, Io $\mathrm{ml}$., are dissolved in $200 \mathrm{ml}$. of water and diluted to $\mathrm{I}, 000 \mathrm{ml}$. with water.

Lead Substandards These must be prepared daily from the standard. All water used was purified by ion exchange in a Dee Minizer apparatus.

Hydrochloric acid, conc., nitric acid, conc., sulphuric acid, conc., ammonia, conc., hydrogen peroxide, and isobutylmethylketone were from Merck, Darmstadt; APDC was from $\mathrm{K} \& \mathrm{~K}$ Laboratories or Hopkins \& Williams, Ltd.; lead nitrate was from Riedel de Haen A.G.

\section{Analytical Procedure}

I. The urine samples were collected and stored in plastic bottles containing $5 \mathrm{~N}$ hydrochloric acid to prevent decomposition of the urine and loss of metal by precipitation. Twenty-five to thirty millilitres of acid were adequate for a 24-hour urinary volume (up to $2,500 \mathrm{ml}$.). Acidified in this way and frozen, the urine samples can be stored for a long time. Thus, the dithizone method showed no losses of lead when the samples were stored for from six to I I months.

2. In a test tube containing two or three glass beads, Io $\mathrm{ml}$. of urine and $5 \mathrm{ml}$. of digestion reagent were heated over a small flame. Any tendency to froth was controlled by adding, e.g., a few drops of octyl alcohol. After cessation of a grey-white smoke the solution was allowed to cool for a few minutes. Two millilitres of hydrogen peroxide were added and the ashing process was continued. If necessary, further portions of hydrogen peroxide were added and ashing was repeated until the solution was colourless or very slightly yellow. Heating was then continued for a further io to 15 minutes.

3. The sample was transferred, with washings to a total of $30 \mathrm{ml}$., to a separating funnel, and the $\mathrm{pH}$ was adjusted to about 3.0 by the drop-wise addition of concentrated ammonia. (Using saturated sodium hydroxide the degree of lead extraction was incomplete and variable.) The $p H$ need be only approximately adjusted, as the extraction efficiency was unchanged from $p \mathrm{H} 2.5$ to 4.5 (Fig. I), in agreement with other findings (Malissa and Schoeffmann, I955; Sprague and Slavin, 1964; Mansell, 1965). Willis' (I962) finding that the optimal $\mathrm{pH}$ was different for extraction from water and urine is irrelevant here, as both standards and urine samples were ashed in the same way.

4. One millilitre of $2 \%$ APDC solution was added, mixed, and allowed to stand for five minutes.

5. Five millilitres of isobutylmethylketone saturated with water were added, and the mixture was shaken for Io minutes, using a shaking machine. The phases separated in five to Io minutes, after which the water phase was run off almost completely.

6. The remaining contents of the funnel were centrifuged for to minutes at 3,000 r.p.m., and the isobutylmethylketone phase was aspirated carefully. It 


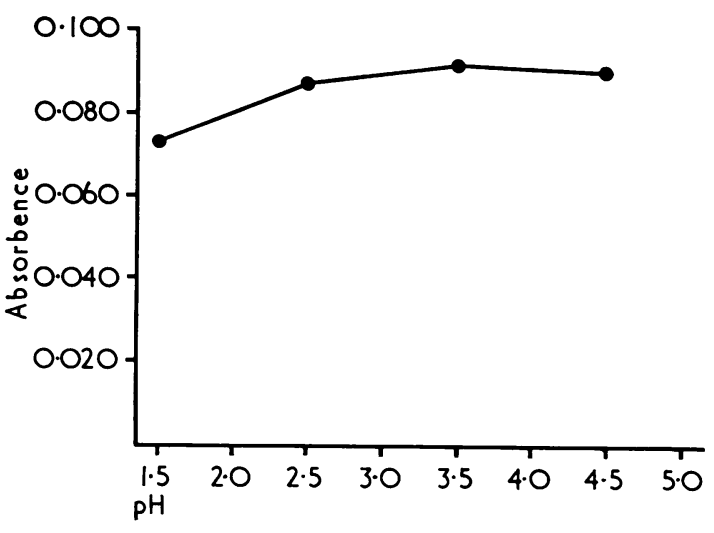

FIG. I. Effect of $p H$ on the efficiency of extraction of lead from ashed water standards and urine samples with a lead concentration of $0.4 \mu \mathrm{g} . / \mathrm{ml}$.

is very important that none of the water phase accompanies it. For safety some isobutylmethylketone was left, since a quantitative recovery is not necessary.

The sample was then ready for analysis. This had to be carried out at once. When the sample was allowed to stand overnight there was a great reduction in absorbence. Before measuring the absorbence the instruments, including the burner, were warmed up for 15 minutes. During aspiration of water-saturated solvent the fuel flow was adjusted to give a very slightly yellow flame, and the absorption was set at zero.

Standard Graphs and Choice of Wavelength Standard lead solutions were analysed in exactly the same manner as the urine samples to provide a calibration curve such as that shown in Figure 2. For lead

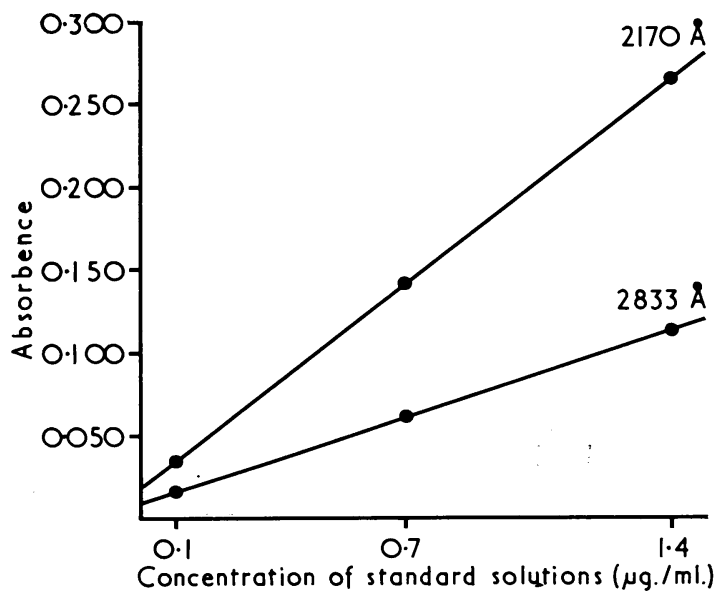

FIG. 2. Standard curves for lead in isobutylmethylketone obtained at wavelengths $2170 \AA$ and $2833 \AA$. The lead in $10 \mathrm{ml}$. of aqueous standard solution was extracted into $5 \mathrm{ml}$. of isobutylmethylketone. in isobutylmethylketone the calibration curves were linear up to an absorbence of about 0.250 , which corresponded to a urinary lead concentration of about I.4 $\mu \mathrm{g}$. $/ \mathrm{ml}$. measured at $2170 \AA$, and about $3.2 \mu \mathrm{g} . / \mathrm{ml}$. at $2,833 \AA$. The wavelength used depended on the concentration of lead. When the lead concentration in the urine was expected to be higher than $3 \mu \mathrm{g}$. $/ \mathrm{ml}$., e.g., during treatment of lead poisoning, a smaller volume of urine was taken and diluted. Blanks gave absorbences of 0.018 to 0.020 at $2170 \AA$ and half as much at 2833 $\AA$, corresponding to the points at which the standard curves cross the vertical axis (Fig. 2).

Interference from Light Scattering Light scattering, which gave a false absorption, was studied at $2203.5 \AA$, at which there is no absorption from lead. The signal produced was found to give an absorbence about 0.010. It was the same for both the standards and the urine samples, so there is no need for any correction for this effect as calibration curves were always used.

\section{Results and Discussion}

The results reported here were all obtained from measurements at $2170 \AA$. The urines from patients undergoing treatment for lead poisoning were diluted before analysis.

Sensitivity and Relative Detection Limit An absorption of $\mathrm{I} \%$ was produced by a urinary lead concentration of about $0.02 \mu \mathrm{g} . / \mathrm{ml}$. The sensitivity could be enhanced by using more urine or less organic solvent. The detection limit for lead in urine was about $0.02 \mu \mathrm{g} . / \mathrm{ml}$. with the instrumental settings given ${ }^{1}$ (Fig. 3). Using scale expansion $\times 3$ and a noise suppression setting of

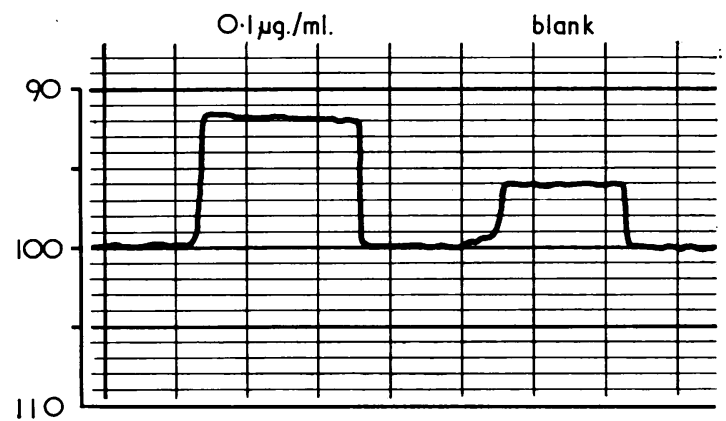

FIg. 3. Absorption traces for $0.1 \mu \mathrm{g} . / \mathrm{ml}$. lead and a blank solution obtained at scale expansion $X I$ and with noise suppression setting 2 .

${ }^{1}$ The recorder traces in Figs. 3 and 4 were obtained with a shielded hollow cathode lamp, which was available at the end of the work. This lamp gives far less background noise than the standard lamp, so that the signal-to-noise ratio was more favourable and the detection limit was lower. 


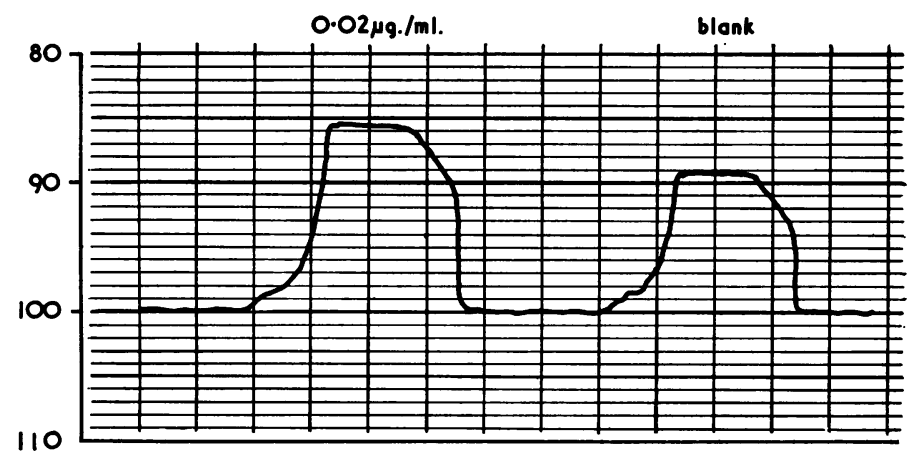

FIG. 4. Absorption traces for $0.02 \mu \mathrm{g} . / \mathrm{ml}$. lead and for a blank solution, obtained at scale expansion $\times 3$ and noise suppression setting 4 .

4, the detection limit could be reduced to below $0.01 \mu \mathrm{g} . / \mathrm{ml} .^{1}$ (Fig. 4). Still greater scale expansion could not be used because the recorder trace was too noisy even with maximal noise suppression. Using scale expansion, the reading took longer and needed a greater sample volume. Such sensitivity is, however, unnecessary for routine analysis of urines with lead concentrations down to $0.05 \mu \mathrm{g} . / \mathrm{ml}$., and for analysis of lower lead concentrations it may be preferable to concentrate the metal further in the organic solvent, as described above.

Precision of the Method The error of a single estimation was calculated from duplicate estimations on 32 urine samples with lead concentrations from 5 to $\mathrm{I} 18 \mu \mathrm{g}$. $/ 100 \mathrm{ml}$. (0.05 to I.I8 $\mu \mathrm{g} . / \mathrm{ml}$.). Seven samples were from workers with suspected lead exposure, nine from workers exposed to lead, and I6 from patients with lead poisoning undergoing treatment with sodium calciumedetate (Io cases) or penicillamine (6 cases). Five samples were fresh specimens, I I were one to two weeks old, 12 were one to two months old, and four were almost one year old.

The standard error of a single determination was $\mathrm{I} \cdot 29 \mu \mathrm{g}$. / $\mathrm{IOO} \mathrm{ml}$. over the whole range. In the range 5.0 to $28.0 \mu \mathrm{g}$. $/ 100 \mathrm{ml}$, the standard error was $\mathrm{I} \cdot 28 \mu \mathrm{g}$. $/ \mathrm{r} 00 \mathrm{ml}$. The I6 samples within this range were one to 14 days old and none was from any of the patients undergoing treatment. In the range 47.0 to $1 \mathrm{I} 8.0 \mu \mathrm{g} . / 100 \mathrm{ml}$. the standard error was I. $29 \mu \mathrm{g}$. $/ 100 \mathrm{ml}$. These I6 samples were one to I I months old and from patients treated with chelating agents.

Comparison with Dithizone Method (Fig. 5) On 28 urine samples a comparison was made between the values obtained with the method described above and the colorimetric dithizone extraction method of Bessman and Layne (I955). This method has been used in the laboratory for several years. The standard error of a single determination was $\mathrm{I} \cdot 6 \mu \mathrm{g}$./100 ml., calculated from duplicate determinations on 50 consecutive urine samples.

The results of the comparison are given in the Table. The differences between the values obtained with the two methods seemed to be greater for the samples from patients treated with sodium calciumedetate. This was confirmed by an analysis of variance $(F=12.97 ; P<0.01)$. The differences for the samples from patients treated with penicillamine were like those for the fresh samples from the untreated patients. These two groups were there-

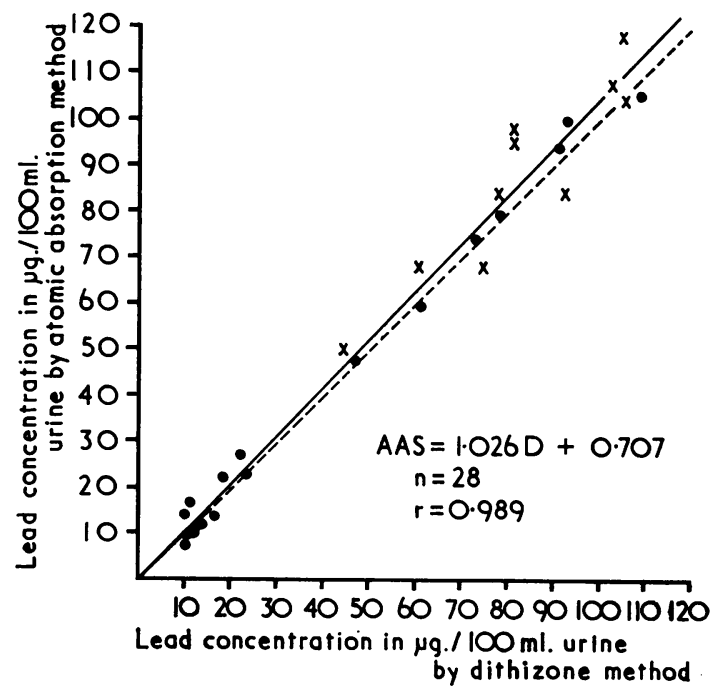

FIG. 5. Comparison of dithizone (D) and AAS methods for determination of lead in urine. The dotted line is the line of identity.

O samples from patients treated with penicillamine or without treatment.

$\times$ samples from patients treated with sodium calciumedetate. 
TABLE

Differences between Lead Content of Urine as Estimated By Two Methods

\begin{tabular}{|c|c|c|c|c|}
\hline $\begin{array}{c}\text { Dithizone } \\
(\mu \mathrm{g} . / \\
\text { roo ml. })\end{array}$ & $\begin{array}{c}A A S \\
(\mu g . / \\
\text { IOO ml. })\end{array}$ & $\begin{array}{c}\text { Differ- } \\
\text { ence }\end{array}$ & $\begin{array}{c}\text { Age of } \\
\text { Urine } \\
\text { Sample }\end{array}$ & Treatment \\
\hline $\begin{array}{l}10 \\
10 \\
10 \\
\text { I1 } \\
12 \\
12 \\
13 \\
16 \\
19 \\
23 \\
24\end{array}$ & $\begin{array}{r}14 \\
8 \\
10 \\
16 \\
10 \\
11 \\
12 \\
14 \\
23 \\
27 \\
24\end{array}$ & $\begin{array}{r}+4 \\
-2 \\
0 \\
+5 \\
-2 \\
-1 \\
-1 \\
-2 \\
+4 \\
+4 \\
0\end{array}$ & $\begin{array}{l}\text { I day } \\
6 \text { days } \\
7 \text { days } \\
\text { I day } \\
6 \text { days } \\
6 \text { days } \\
5 \text { days } \\
6 \text { days } \\
\text { I day } \\
\text { I day } \\
\text { I day }\end{array}$ & $\begin{array}{c}\text { None } \\
\text {, } \\
\text {, } \\
\text {, } \\
\text {, } \\
\text { ", } \\
\text {, } \\
\text {, }\end{array}$ \\
\hline $\begin{array}{r}47 \\
61 \\
73 \\
79 \\
92 \\
93 \\
109\end{array}$ & $\begin{array}{r}48 \\
60 \\
74 \\
80 \\
94 \\
99 \\
106\end{array}$ & $\begin{array}{l}+\mathbf{I} \\
-1 \\
+1 \\
+1 \\
+2 \\
+6 \\
-3\end{array}$ & $\begin{array}{l}\text { I I months } \\
6 \text { weeks } \\
\text { I month } \\
\text { Io months } \\
\text { I I months } \\
\text { I month } \\
\text { Io months }\end{array}$ & $\begin{array}{c}\text { Penicillamine } \\
\text { ", } \\
\text { ", } \\
\text { ", } \\
\text { ", }\end{array}$ \\
\hline $\begin{array}{r}45 \\
61 \\
75 \\
79 \\
82 \\
82 \\
93 \\
103 \\
106 \\
106\end{array}$ & $\begin{array}{r}50 \\
68 \\
68 \\
83 \\
96 \\
98 \\
83 \\
107 \\
105 \\
118\end{array}$ & $\begin{array}{l}+5 \\
+7 \\
-7 \\
+4 \\
+14 \\
+16 \\
-10 \\
+4 \\
-1 \\
+12\end{array}$ & $\begin{array}{l}\text { I month } \\
\text { I month } \\
\text { I month } \\
\text { I month } \\
\text { I month } \\
\text { I month } \\
\text { I month } \\
\text { I month } \\
\text { I month } \\
2 \text { months }\end{array}$ & $\begin{array}{c}\text { Sodium } \\
\text { calciumedetate } \\
\text {," } \\
\text { ", } \\
\text { ", } \\
\text { ", } \\
\text { ", } \\
\text { ", } \\
\text { ", }\end{array}$ \\
\hline
\end{tabular}

fore pooled. The equation of the regression line was: AAS $=1.0038 \mathrm{D}+0.738$, and the correlation coefficient was 0.997 , where AAS and D are the concentrations in $\mu \mathrm{g} . / 100 \mathrm{ml}$. found by the two methods. For these two groups the two methods gave identical results. For the samples from patients treated with sodium calciumedetate the regression equation was: $\mathrm{AAS}=0.969 \mathrm{D}+6.963$, and the correlation coefficient was 0.915 . In this group the AAS values seemed to be somewhat higher than the colorimetric ones, but the regression line was not significantly different from the line of identity.

For simplicity, although it is not without objection from a statistical point of view, we have in Fig. 5 given the regression line and the correlation coefficient for all the values (AAS $=\mathbf{r} \cdot 026 \mathrm{D}+$ $0.707 ; r=0.989$ ).

The conclusion is that there was very good agreement between the results obtained with the two methods, but that the differences were significantly greater when the patients were undergoing treat- ment with sodium calciumedetate. This effect was, however, small and of no practical importance.

Neither method is very simple but, in our experience, the dithizone method is more timeconsuming. Furthermore, the extraction technique used with AAS allows determinations of lower lead concentrations, as the lead in large volumes of urine can be concentrated into a small volume of $i$ sobutylmethylketone. The combination of wet ashing and extraction into an organic solvent may seem too elaborate. However, simple extraction is unsatisfactory for organically bound lead, where the leadbinding properties of APDC may be inferior to those of the urine constituents, especially if the urine is obtained during treatment with chelating agents.

\section{REFERENCES}

Allan, J. E. (196I). The use of organic solvents in atomic absorption spectrophotometry. Spectrochim. Acta, 17, 467-473.

Berman, E (1964). The determination of lead in blood and urine by atomic absorption spectrophotometry. Atomic Absorption Newsletter, 3, I I I-I I4.

Bessman, S. P., and Layne, E. C., Jr. (1955). A rapid procedure for the determination of lead in blood or urine in the presence of organic chelating agents. F. Lab. clin. Med., 45, 159-166.

Malissa, H., and Schoeffmann, E. (1955). On the use of substituted dithiocarbamates in microanalysis. Mikrochim. Acta, pp. 187-202.

Mansell, R. E. (1965). Notes on the extraction of manganese with chelating agents and MIBK. Atomic Absorption Newsletter, 4, 276-277.

Pierce, J. O., and Cholak, J. (1966). Lead, chromium and molybdenum by atomic absorption. Arch. environm. Hlth, 13, 208-212.

Slavin, W. (1965). Applications of optical absorption spectroscopy to analytical biochemistry and toxicology. Occup. Hlth Rev., 17, 9-18.

- (1966). An atomic absorption bibliography. Atomic Absorption Newsletter, 4, I-19.

- , and Sprague, S. (1964). The determination of trace metals in blood and urine by atomic absorption spectrophotometry. Ibid., 3, 1-6.

$\longrightarrow,-$ Rieders, F., and Cordova, V. (1964). The determination of certain toxicological trace metals by atomic absorption spectrophotometry. Ibid., 3, (No. 17) 7-10.

Sprague, S., and Slavin, W. (1964). Determination of very small amounts of copper and lead in $\mathrm{KCl}$ by organic extraction and atomic absorption spectrophotometry. Ibid., no. 20, pp. I I-I5.

Walsh, A. (1955). The application of atomic absorption spectra to chemical analysis. Spectrochim. Acta, 7, I08-II7.

Willis, J. B. (1962). Determination of lead and other heavy metals in urine by atomic absorption spectroscopy. Anal. Chem., 34, 614-617.

- (1965). The analysis of biological materials by atomicabsorption spectroscopy. Clin. Chem., II, 25 I-258.

Zettner, A. (1964). Principles and applications of atomic absorption spectroscopy. Advanc. clin. Chem., 7, 1-62.

-, Sylvia, L. C., and Capacho-Delgado, L. (I966). The determination of serum iron and iron-binding capacity by atomic absorption spectroscopy. Amer. f. clin. Path., 45, 533-540. 